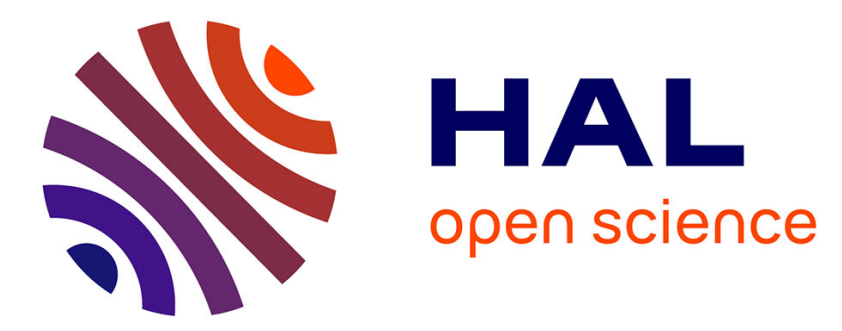

\title{
Photodegradation of Decabromo Diphenyl Ether Flame Retardant in Poly (Acrylonitrile Butadiene Styrene)
} (ABS)

\author{
Hussam Aldoori, Zohra Bouberka, Abdelouahab Nadim, Yassine Agguine, \\ Said Eddarir, Philippe Supiot, Corinne Foissac, Ulrich Maschke
}

\section{To cite this version:}

Hussam Aldoori, Zohra Bouberka, Abdelouahab Nadim, Yassine Agguine, Said Eddarir, et al.. Photodegradation of Decabromo Diphenyl Ether Flame Retardant in Poly (Acrylonitrile Butadiene Styrene) (ABS). Journal of Macromolecular Science Part B Physics, 2020, Journal of Macromolecular Science Part B Physics, 59 (10), pp.609-620. 10.1080/00222348.2020.1763607 . hal-03104368

\section{HAL Id: hal-03104368 https: / hal.univ-lille.fr/hal-03104368}

Submitted on 8 Jan 2021

HAL is a multi-disciplinary open access archive for the deposit and dissemination of scientific research documents, whether they are published or not. The documents may come from teaching and research institutions in France or abroad, or from public or private research centers.
L'archive ouverte pluridisciplinaire HAL, est destinée au dépôt et à la diffusion de documents scientifiques de niveau recherche, publiés ou non, émanant des établissements d'enseignement et de recherche français ou étrangers, des laboratoires publics ou privés. 
2 Photodegradation of Decabromo Diphenyl Ether Flame Retardant in Poly Eddarir $^{\mathrm{a}}$, Philippe Supiot ${ }^{\mathrm{c}}$, Corinne Foissac ${ }^{\mathrm{c}}$, Ulrich Maschke*, ${ }^{\mathrm{a}}$

${ }^{a}$ Unité Matériaux et Transformations - UMET (UMR CNRS N8207), Bâtiment C6, Université de Lille, 59655 Villeneuve d’Ascq Cedex, France

15

c Faculté des Sciences et Technologies, Université de Lille, 59655 Villeneuve d’Ascq Cedex,

Corresponding author :

Emails of the coauthors, in the order of appearance:

hussam.aldoori.etu@univ-lille.fr; bouberkazohra@yahoo.fr; nadimabdelouahab@gmail.com; corinne.foissac@univ-lille.fr 
Decabromodiphenylether (DBDE) is a brominated flame retardant which belongs to the group of polybromodiphenylethers (PBDEs) often used as a fire resistant additive in various well known polymeric systems like polystyrene, poly(acrylonitrile-butadiene-styrene) (ABS), polypropylene, etc. This compound can be considered as a persistent organic pollutant and presents certain risks for the environment owing to the fact that it is bioaccumulable and not biodegradable. A detailed investigation, described here, was carried out on the effect of ultraviolet/visible radiation on DBDE in ABS with the aim to study the photolytic reactions of this molecule in the solid state, in order to improve the economic and ecological treatment of brominated plastic waste from waste electrical and electronic equipment (WEEE). This study presents new aspects of the photochemical degradation of DBDE/ABS systems in the solid state. The photodegradation of DBDE in ABS was followed by Fourier transform infrared spectroscopy (FTIR) as well as by thermogravimetrical analysis (TGA). Good agreement was obtained for the results of both analytical methods in terms of the overall photolysis of DBDE.

Keywords: Photolysis; Polybromodiphenylethers; acrylonitrile-butadiene-styrene; UV-visible radiation; Kinetics. 


\section{Introduction}

Flame retardants (FRs) are necessary to ensure safety in a wide range of applications such as plastics components of electrical equipments, cars and aircrafts, and the main components of insulation materials, foams in furnitures, mattresses, and textiles [1,2]. Brominated FRs (BFRs) represent the largest market group of FRs due to their low cost and high performance efficiency [2,3]. Polybrominated diphenyl ethers (PBDEs) are well known BFRs with three major commercial formulations: DecaBDE (DBDE), OctaBDE (OBDE) and PentaBDE. However, PBDEs have aroused high environmental concern because of their global distribution and bioaccumulation [4-10]. It has been reported that PBDEs influence liver enzyme activity and act as endocrine disruptors, inducing immunotoxicity and affecting neurological development at a key period of brain growth [11-12]. Marketing and use of PentaBDE and OBDE was banned throughout the EU in 2004 on the basis of the potential for the lower-brominated derivatives to bioaccumulate in the environment [13]. Only DBDE is still commercially available in a few countries worldwide. In the EU, DBDE was limited in use in electric and electronic equipment (EEE) from 2002 until 2005, and from 2005 to 2008 it was exempted from the restriction of use in EEE by commission decision 2005/717/EC. Since 30/06/2008, the original Restriction of Hazardous Substances Directive 2002/95/EC (RoHS 1) has been applied again to DBDE, by limiting the concentration of PBDEs to 0.1 weight\% (wt\%). The ROHS II Directive (2011/65/EU) further restricted the use of DBDE in EEE [14]. A new entry 67 was established by the Commission Regulation (EU) 2017/227 in Annex XVII to Regulation (EC) No 1907/2006 of the European Parliament and of the Council (REACH) [15]. Following this entry, DBDE will only be temporally allowed for aerospace and automotive industries, although some exemptions were also given for EEE [16].

DBDE remains one of the most important chemical and environmental pollutants of concern since its emissions to the environment occur particularly during both service life and end-of- 
71 life phases. Removal of this compound from the environment remains a very difficult

72 challenge because DBDE is highly hydrophobic and has very limited solubility in water [17].

73

Major applications of DBDE are in styrenic polymers, polyolefins, polyesters, and nylons as used in textiles. It is also used as an additive flame retardant mainly in poly(acrylonitrile butadiene styrene) (ABS) and their derivatives, in epoxy oligomers and in engineering plastics for electrical and electronic devices. These bromine derivatives are relatively resistant to physical, chemical or biological degradation. Therefore, it is important to understand its degradation processes and fate in the environment, including both photodegradation kinetics and photoproducts. Research investigations have shown that DBDE can be broken down to produce many lighter-weight PBDEs, including three highly accumulative species associated with PentaBDE [8]. Photolysis is an important degradation pathway for some persistent organic pollutants, including PBDEs, in the environment, and has been reported to occur for PBDE under a variety of conditions [18-21]. Watanabe and Tatsukawa [18] for instance, presented a study on the photolysis of DBDE in a mixture of hexane, benzene, and acetone (8:1:1) employing both sunlight and artificial UV light. Their results indicated that DBDE undergoes photodegradation by reductive debromination and that brominated dibenzofurans (PBDFs) represent the major products from photolysis. Recently, some reports were published on photolysis of DBDE in toluene and adsorbed on silica gel, sand, soil and sediments that showed similar results of photolytic debromination [22-27]. These groups found that the photochemical reaction rate decreased with decreasing bromination degree and that it might also be affected by the positions of the substituted Br-atoms. However, the photolytic decomposition and the effect of photolytic factors on the photodegradation reaction of PBDEs in the solid state have not been well documented in the literature.

In the light of the above discussion, since the feasibility of the photolytic degradation in the liquid state has already been shown, this report focuses on the debromination of DBDE in the 
solid state. In particular, DBDE was dispersed in various concentrations in an ABS (0-30 wt\%) before undergoing UV-Visible irradiation. These percentages were chosen since they correspond to concentrations of BFRs in polymers from waste EEE.

To the best of our knowledge this topic has not been reported before in the literature. In this work two analytical methods were employed in order to compare and correlate the corresponding results. Infrared spectroscopy and thermogravimetrical analysis techniques were found to be particularly well adapted since they allow characterization of the solid samples without further treatment.

\section{Materials and Methods}

\subsection{Materials}

DBDE (Saytex 102E, purity 98\%, CAS: 1163-19-5), 2,2',3,3',4,4',5,5’,6,6’Decabromodiphenylether (BDE-209), $\left(\mathrm{C}_{12} \mathrm{Br}_{12} \mathrm{O}\right)$, was purchased from Albemarle Corp. (USA), it was a white to off-white powder.

The poly(acrylonitrile butadiene styrene) (ABS) was obtained from a recycling plant situated in the "Région Hauts de France"; mixtures of the ABS with different amounts of DBDE (10wt\%, 15wt\%, 20wt\% and 30wt\%) were prepared using a micro-extrusion machine followed by crushing the obtained samples to obtain fine powders. The average diameter size of all powders was between 600 and $800 \mu \mathrm{m}$.

\subsection{Photolytic experiments}

The irradiation process was carried out at room temperature, using a 150W Xenon light source LC8 from Hamamatsu Photonics France S.A.R.L. together with an optical fiber, characterized by an emission spectrum covering nearly the whole UV-Visible spectrum with a broad maximum in the visible range. The distance between the end of the optical fiber of the 
121 UV-Visible source and the sample was kept constant at $3 \mathrm{~cm}$.

122 During the photodegradation experiments thin layers of the powdered materiel (ABS and

123 ABS/DBDE blends) were placed on a flat sample holder which was kept under controlled

124 agitation to renew regularly the sample surface. At the appropriate exposure times, without

125 interruption (i.e., there was no conduction of cumulative experiments), the photodegradation

126 reaction was finished by removing the solid samples from the light exposure and immediately

127 initiating analysis. All experiments were repeated at least two times and averaged values are 128 presented in the corresponding figures.

129 It is well known that irradiation sources generally provide not only a certain amount of 130 photons as function of their UV-Vis spectrum, light intensity and exposure time, but also 131 quite frequently an increase in temperature of the sample medium due to the infrared part of

132 the spectrum. Using the experimental set-up described above, the maximum temperature 133 reached on the surface of the sample was found as $\mathrm{T}=50^{\circ} \mathrm{C}$. In order to evaluate eventual

134 thermal degradation effects occurring at this temperature in the absence of light, ABS/DBDE 135 samples underwent an isothermal treatment at $\mathrm{T}=50^{\circ} \mathrm{C}$ for one hour in a furnace; these 136 samples were then kept in darkness until analysis was performed by Fourier transform

137 infrared spectroscopy. No thermal degradation of the investigated ABS/DBDE system was 138 detected.

\subsection{Physico-chemical analysis}

$141 \quad$ 2.3.1 Fourier transform infrared spectroscopy (FTIR)

142 FTIR spectra were recorded in transmission mode at room temperature, using a model 2000

143 spectrometer (Perkin Elmer Corp., USA). The spectral range between $400 \mathrm{~cm}^{-1}$ and $4000 \mathrm{~cm}^{-1}$

144 was investigated. The number of accumulated scans was 16 with a spectral resolution of

$1454 \mathrm{~cm}^{-1}$. Solid $\mathrm{KBr}$ disks of diameter one centimeter and thickness one millimeter were used, 
146 formed by mixing 10mg of the powder sample to be analyzed with 90mg of dried $\mathrm{KBr}$. A

147 pressure of 8bars was applied during $5 \mathrm{~min}$ to prepare the $\mathrm{KBr}$ disks.

148

149

2.3.2 Thermogravimetric analysis (TGA)

150

Thermogravimetric analysis (TGA) was conducted using Pyris 1 instrument (Perkin Elmer)

151 exhibiting a mass resolution of $1 \mu \mathrm{g}$. The average mass of the samples was $8 \mathrm{mg}$, placed in

152 Platinium-HT-pans. Thermal analysis of the powder samples was performed under nitrogen atmosphere during a heating ramp of $10^{\circ} \mathrm{C} / \mathrm{min}$ in the temperature range between $20^{\circ} \mathrm{C}$ and $900^{\circ} \mathrm{C}$.

\section{Results and discussion}

\subsection{Spectroscopic observations of the photolysis of ABS/DBDE}

158

159

160

161

162

163

164

FTIR spectra of ABS, DBDE, and ABS/DBDE blends are presented in Figs. 1 and 2, allowing to identify and to select characteristic bands of DBDE and ABS. In the wavenumber range between 1025 and $1800 \mathrm{~cm}^{-1}$ as shown in Fig. 1a, ABS presents bands at $1453 \mathrm{~cm}^{-1}, 1494 \mathrm{~cm}^{-1}$ and $1602 \mathrm{~cm}^{-1}$, all of which can be attributed to C-C stretching vibrations in the aromatic rings of the styrene part in ABS [28]. In the same wavenumber range, DBDE exhibits a broad intense band located between $1250 \mathrm{~cm}^{-1}$ and $1370 \mathrm{~cm}^{-1}$, corresponding to asymmetric C-O-C stretching vibrations in the aromatic rings of DBDE [29]. This band, which present no interference with other bands in the DBDE spectrum and does not exist for ABS, can thus be selected to follow the DBDE photodegradation kinetics. With an increase of the concentration of $\mathrm{DBDE}$ in the ABS/DBDE blends, the intensity of this band, characteristic of the ether groups, increased correspondingly, as shown in Fig. 1b.

Insert Figure 1 here

Insert Figure 2 here 
171 Figure 2 presents the FTIR spectra of DBDE and ABS in the wavenumber range between 480

172 and $1000 \mathrm{~cm}^{-1}$. Some absorbance bands of ABS and DBDE appear rather close, such as the 173 bands at $966 \mathrm{~cm}^{-1}$ (C-H in trans-butadiene part of ABS [30]) and $960 \mathrm{~cm}^{-1}$ (C-Br [29] in

174 DBDE); $765 \mathrm{~cm}^{-1}\left(\mathrm{CH}_{2}\right.$ in vinyl-butadiene and styrene part of ABS [28]) and $761 \mathrm{~cm}^{-1}$ (C-C 175 ring [31] in DBDE); and $699 \mathrm{~cm}^{-1}$ (C-C ring [32]) and $708 \mathrm{~cm}^{-1}$ (C-C ring [31] in DBDE), 176 respectively. In ABS/DBDE mixtures these overlapping bands cannot be used to follow the 177 effects of photolysis. Only the absorbance band at $617 \mathrm{~cm}^{-1}$ of DBDE, corresponding to 178 aromatic C-Br vibrations [33], does not interfere with ABS bands and will also be considered 179 in following the debromination process. Insert Figure 3 here

181 The model mixtures ABS/DBDE were subjected to a radiative UV/Vis treatment by the

182 Xenon LC8 lamp at room temperature. The infrared spectral analysis of the impact of the 183 radiation on ABS loaded with 30wt\% DBDE is shown in Fig. 3. A relatively strong reduction of the band corresponding to the ether-bond of DBDE was observed after an irradiation time

185 of one hour, accompanied by the appearance of a new band at $1400 \mathrm{~cm}^{-1}$. The kinetics of 186 DBDE degradation was fast in the first few minutes of photolysis, but the reaction rate 187 became relatively slow beyond $10 \mathrm{~min}$ of irradiation. A fast increase of the peak situated at $1881400 \mathrm{~cm}^{-1}$ in the first ten minutes was also observed. This new absorption band is due to the 189 formation of aromatic C-H-groups belonging to photoproducts of DBDE and, in particular, 190 lower brominated BDE.

192 In Fig. 4 one notices a significant reduction of the absorbance band at $1080 \mathrm{~cm}^{-1}$, after one 193 hour of irradiation. This band is associated with an aryl-Br valence vibration from DBDE 194 [34]. This can be explained by the change of the chemical environment of the aromatic nuclei 
of DBDE under the effect of the photolysis. Since DBDE is entirely brominated, one can

196 already see the radiative effect on the debromination of the molecule.

In Fig. 5a one notices a strong reduction of the $\mathrm{C}-\mathrm{Br}$ absorbance band situated at $617 \mathrm{~cm}^{-1}$,

199 allowing thus to confirm the debromination effects on DBDE during photolysis. In Fig. 5b 200 one observes a slight decrease of the intensities of the absorbance bands situated at 557 and $201678 \mathrm{~cm}^{-1}$, related to $\mathrm{C}-\mathrm{Br}$ stretching bands (see for example [35]). One should keep in mind that the latter bands interfere with absorbance bands of ABS, in contrast to the peak from DBDE at $617 \mathrm{~cm}^{-1}$, which does not interfere with ABS bands (see also Fig. 2).

The effect of UV/Vis irradiation was compared between the two systems ABS/20wt\% DBDE and ABS/30wt\% DBDE, by following the decrease of the absorbance band at $1350 \mathrm{~cm}^{-1}$ (Fig. 6). The conversion values from DBDE to lower brominated species were calculated by taking into account the heights of the peak maxima: $\left(\mathrm{H}_{t}-\mathrm{H}_{0}\right) / \mathrm{H}_{0}$, where $\mathrm{H}_{\mathrm{t}}$ and $\mathrm{H}_{0}$ correspond to the peak heights of the irradiated and pristine sample, respectively. It should be mentioned that this approach represents only a fair estimation of the conversion, since the absorbance band 210 considered here might undergo overlapping effects with other bands, especially when 211 photolysis proceeds. In Fig. 6, one notices that the conversion of the band at $1350 \mathrm{~cm}^{-1}$ of the $212 \mathrm{ABS} / 20 \mathrm{wt} \% \mathrm{DBDE}$ system was slightly faster and greater than that of the ABS/30wt\%DBDE 213 system, showing that the initial concentration of DBDE in the polymer can influence the 214 degradation process.

\subsection{Thermal analysis of the ABS/DBDE system before and after photodegradation}

218 The thermograms shown in Fig. 7, obtained by thermogravimetrical analysis (TGA), represent 219 the thermal degradation of ABS and an ABS/DBDE mixture (ABS/10wt\% DBDE). The 
thermal behavior of the ABS/DBDE blend was also examined after photolysis (exposure time:

$22160 \mathrm{~min}$ ). The onset temperature (intersection of the tangent of the beginning of the degradation

222 with the base line) of the thermal degradation of ABS was found to be slightly higher than

223 that of the ABS/DBDE blend: The thermal degradation of ABS started at approximately

$224340^{\circ} \mathrm{C}$, whereas the $\mathrm{ABS} / \mathrm{DBDE}$ mixture started to degrade thermally around $300^{\circ} \mathrm{C}$. The

225 thermal degradation of the ABS/DBDE mixture and ABS proceeded in two steps, the first

226 important one around $400^{\circ} \mathrm{C}$, and the second one around $500^{\circ} \mathrm{C}$. In the case of $\mathrm{ABS}$, the latter

227 step can be explained by different factors as indicated in [36], but also by degradation of

228 crosslinked species formed during the first step [37].

229 An important difference in mass loss was observed for the second degradation step when

230 comparing the results from ABS with the ABS/10wt\% DBDE mixture before irradiation,

231 indicating that the thermal degradation of DBDE occurred primarily during this step. It can be

232 suggested that DBDE was completely pyrolyzed since the weight loss corresponded to $23310 w t \%$.

235 Figure 7 also reveals that photolysis of the ABS/DBDE system resulted in a significant 236 decrease of the second process of the thermal degradation of the sample, compared to the 237 situation before irradiation. These results can be explained by the photolytic degradation of 238 DBDE in the ABS since in the temperature range between approximately $450^{\circ} \mathrm{C}$ and $600^{\circ} \mathrm{C}$, 239 the thermal degradation curve of the irradiated ABS/DBDE system became very close to that 240 of ABS. However, brominated species were still present in the irradiated sample as indicated 241 by the slow decrease of the thermal degradation beyond $600^{\circ} \mathrm{C}$ up to $900^{\circ} \mathrm{C}$, probably due to 242 the presence of aggregates. 
243 Interestingly, similar results were obtained from the pristine and irradiated ABS/DBDE blend

244 for the first degradation step indicating that the polymer remained thermally stable after 245 photolysis.

\section{4. Conclusions}

248 A simple, effective method was presented to destroy DBDE molecules used as flame retardant 249 and to obtain less harmful molecules in the environment. The proposed method comprises the 250 photo-irradiation of ABS/DBDE mainly by visible light, without prior addition of additives 251 such as oxidants or catalysts like $\mathrm{TiO}_{2}$. Two analytical methods were employed which were 252 particularly suited for solid state characterization: Fourier transform infrared spectroscopy and 253 thermogravimetrical analysis. They allowed us to follow the photodegradation of model 254 mixtures comprised of ABS and DBDE. The results indicated that DBDE could be effectively 255 degraded to a considerable extent in the solid state during the recycling process by UV256 Visible irradiation, while the ABS polymer kept its properties, and could thus be reused from 257 brominated WEEE.

\section{Acknowledgements}

260 This work was accomplished in the framework of an international research program. The 261 authors gratefully acknowledge the support of the Algerian Ministry of Higher Education and 262 Scientific Research, the University of Sciences and Technology of Oran/Algeria, the French 263 Centre National de la Recherche Scientifique, and the University of Lille/France. 


\section{References}

266 [1] Alaee, M. I.; Arias, P.; Sjödin, A.; Bergman, Å. An overview of commercially used 267 brominated flame retardants, their applications, their use patterns in different countries/regions and possible modes of release. Environ. Int. 2003, 29, 683-689. DOI: 10.1016/S0160-4120(03)00121-1.

[2] Brominated Flame Retardants; Eljarrat, E., Barceló, D., Eds. Berlin, Heidelberg: Springer-Verlag, 2011.

272 [3] European Flame Retardants Association. http://www.ecetoc.org/links/efra-europeanflame-retardants-association/ (accessed January 9, 2019).

[4] Watanabe, I.; Sakai, S.-I.; Environmental release and behavior of brominated flame retardants. Environ. Int. 2003, 29, 665-682. DOI: 10.1016/S0160-4120(03)00123-5.

276 [5] Olisah, C.; Okoh, O. O.; Okoh A. I. A bibliometric analysis of investigations of polybrominated diphenyl ethers (PBDEs) in biological and environmental matrices from 1992 - 2018. Heliyon 2018, 4, e00964. DOI: 10.1016/j.heliyon.2018.e00964.

[6] Andrade, N. A.; McConnell, L. L.; Anderson, M. O.; Torrents, A.; Ramirez, M. 280 Polybrominated diphenyl ethers: Residence time in soils receiving biosolids application. Environ. Poll. 2017, 222, 412-422. DOI: 10.1016/j.envpol.2016.12.014.

[7] Mai, B.; Chen, S.; Luo, X.; Chen, L.; Yang, Q.; Sheng, G.; Peng, P.; Fu, J.; Zeng, E. Distribution of polybrominated diphenyl ethers in sediments of the Pearl River Delta and adjacent South China Sea. Environ. Sci. Technol. 2005, 39, 3521-3527. DOI: 10.1021/es048083x.

[8] De Wit, C.A. An overview of brominated flame retardants in the environment. Chemosphere 2002, 46, 583-624. DOI: 10.1016/S0045-6535(01)00225-9. 
[9] Ikonomou, M. G.; Rayne, S.; Addison, R. F. Exponential increases of the brominated flame retardants, polybrominated diphenyl ethers, in the Canadian Arctic from 1981 to 2000. Environ. Sci. Technol. 2002, 36, 1886-1892. DOI: 10.1021/es011401x.

[10] Wang, Y.; Liu, H.; Zhao, C.; Liu, H.; Cai, Z.; Jiang, G. Quantitative structure-activity relationship models for prediction of the toxicity of polybrominated diphenyl ether congeners. Environ. Sci. Technol. 2005, 39, 4961-4966. DOI: 10.1021/es050017n.

[11] Meerts, I. A.; Letcher, R. J.; Hoving, S.; Marsh, G.; Bergman, A.; Lemman, J. G.; van der Burg, B.; Brouwer, A. In vitro estrogenicity of polybrominated diphenyl ethers, hydroxylated PDBEs, and polybrominated bisphenol A compounds. Environ. Health Perspect. 2001, 109, 399-409. DOI: 10.1289/ehp.01109399.

[12] Li, F.; Yang, X.; Chen, J.; Lyakurwa, F. Chapter 17 - QSARs on the Thyroid Hormone Effects of Polybrominated Diphenyl Ether (PBDE) Derivatives. Compr. Anal. Chem. 2015, 67, 547-586. DOI: 10.1016/B978-0-444-63299-9.00017-X.

[13] P. Cox and P. Efthymiou, Directive 2003/11/EC of the European parliament and of the council of February 6, 2003 amending for the 24th time. Council Directive 76/669/EEC relating to restrictions on the marketing and use of certain dangerous substances and preparations (pentabromodiphenyl ether, octabromodiphenyl ether) (Official Journal Legislative 42, 45 (2003)).

[14] Directive 2011/65/EU of the European Parliament and of the Council of 8 June 2011 on the restriction of the use of certain hazardous substances in electrical and electronic equipment (RoHS 2) (Official Journal Legislative 174, 01/07/2011, p. 88).

[15] Regulation (EC) No 1907/2006 of the European Parliament and of the Council of 18 December 2006 concerning the Registration, Evaluation, Authorisation and Restriction of Chemicals (REACH), establishing a European Chemicals Agency, amending Directive 1999/45/EC and repealing Council Regulation (EEC) No 793/93 and 
Commission Regulation (EC) No 1488/94 as well as Council Directive 76/769/EEC and Commission Directives 91/155/EEC, 93/67/EEC, 93/105/EC and 2000/21/EC (Official Journal Legislative 396, 30/12/2006, p. 1).

[16] Commission Regulation (EU) 2017/227 of 9 February 2017 amending Annex XVII to Regulation (EC) No 1907/2006 of the European Parliament and of the Council concerning the Registration, Evaluation, Authorisation and Restriction of Chemicals (REACH) as regards bis(pentabromophenyl)ether (Official Journal Legislative 35, 10/02/2017, p. 6).

[17] De Wit, C. A.; Herzke, D.; Vorkamp, K. Brominated flame retardants in the Arctic environment--trends and new candidates. Sci. Total Environ. 2010, 408, 2885-2918. DOI: 10.1016/j.scitotenv.2009.08.037.

[18] Watanabe, I.; Tatsukawa, R. Formation of brominated dibenzofurans from the photolysis of flame retardant decabromobiphenyl ether in hexane solution by UV and sun light. Bull. Environ. Contam. Toxicol. 1987, 39, 953-959. DOI: 10.1007/ BF01689584.

[19] Söderstrom, G.; Sellström, U.; De Wit, C. A.; Tysklind, M. Photolytic debromination of decabromodiphenyl ether (BDE 209). Environ. Sci. Technol. 2004, 38, 127-132. DOI: 10.1021/es034682c.

[20] Bezares-Cruz, J.; Jafvert, C. T.; Hua, I. Solar photodecomposition of decabromodiphenyl ether: products and quantum yield. Environ. Sci. Technol. 2004, 38, 4149-4156. DOI: 10.1021/es049608o.

[21] Hua, I.; Kang, N.; Jafvert, C. T.; Fabrega-Duque, J. R. Heterogeneous photochemical reactions of decabromodiphenyl ether. Environ. Toxicol. Chem. 2003, 22, 798-804. DOI: $10.1002 /$ etc.5620220418. 
[22] Ye, W.; Shao, Y.; Hu, X.; Liu, C.; Sun, C. Highly Enhanced Photoreductive Degradation of Polybromodiphenyl Ethers with $\mathrm{g}-\mathrm{C}_{3} \mathrm{~N}_{4} / \mathrm{TiO}_{2}$ under Visible Light Irradiation. Nanomaterials 2017, 7, 76. DOI: 10.3390/nano7040076.

[23] Sun, C.Y.; Chang, W.; Ma, W.H.; Chen, C.C.; Zhao, J.C. Photoreductive Debromination of Decabromodiphenyl Ethers in the Presence of Carboxylates under Visible Light Irradiation. Environ. Sci. Technol. 2013, 47, 2370-2377. DOI: 10.1021/es3045604.

[24] Ahn, M. Y.; Filley, T. R.; Jafvert, C. T.; Nies, L.; Hua, I.; Bezares-Cruz J. Photodegradation of Decabromodiphenyl Ether Adsorbed onto Clay Minerals, Metal Oxides, and Sediment. Environ. Sci. Technol. 2006, 40, 215-220. DOI: 10.1021/es051415t.

[25] Tokarz, J. A.; Ahn, M. Y.; Leng, J.; Filley, T. R.; Nies, L. Reductive debromination of polybrominated diphenyl ethers in anaerobic sediment and a biomimetic system. Environ. Sci. Technol. 2008, 42, 1157-1164. DOI: 10.1021/es071989t.

[26] Keum, Y. S.; Li, Q. X. Reductive Debromination of Polybrominated Diphenyl Ethers by Zerovalent Iron. Environ. Sci. Technol. 2005, 39, 2280-2286. DOI: 10.1021/es048846g.

[27] Kim, E.-J.; Kim, J.-H.; Kim, J.-H.; Bokare, V.; Chang, Y.-S. Predicting reductive debromination of polybrominated diphenyl ethers by nanoscale zerovalent iron and its implications for environmental risk assessment. Sci. Total Environ. 2014, 470-471, 1553-1557. DOI: 10.1016/j.scitotenv.2013.07.038.

[28] Saviello, D.; Pouyet, E.; Toniolo, L.; Cotte M.; Nevin, A. Synchrotron-based FTIR microspectroscopy for the mapping of photo-oxidation and additives in acrylonitrilebutadiene-styrene model samples and historical objects. Anal. Chim. Acta 2014, 843, 59-72. DOI: 10.1016/j.aca.2014.07.021. 
[29] Zhang, K.; Huang, J.; Wang, H.; Yu, G.; Wang, B.; Deng, S.; Kano, J.; Zhang, Q. Mechanochemical destruction of decabromodiphenyl ether into visible light photocatalyst BiOBr. RSC Adv. 2014, 4, 14719-14724. DOI: 10.1039/C3RA47738J.

[30] Nagle, D.J.; Celina, M.; Rintoul, L.; Fredericks, P.M. Infrared microspectroscopic study of the thermo-oxidative degradation of hydroxy-terminated polybutadiene/isophorone diisocyanate polyurethane rubber. Polym. Degrad. Stab. 2007, 92, 1446-1454. DOI: 10.1016/j.polymdegradstab.2007.05.010.

[31] Chruszcz-Lipska, K.; Trzewik, B.; Winid, B. Molecular structure and vibrational spectra of 2,2',4,4',6-pentabromodiphenyl ether (BDE 100). Spectrochim. Acta A 2017, 182, 5057. DOI: 10.1016/j.saa.2017.03.049.

[32] Bokria, J.G.; Schlick, S. Spatial effects in the photodegradation of poly(acrylonitrilebutadiene-styrene): a study by ATR-FTIR. Polymer 2002, 43, 3239-3246. DOI: 10.1016/S0032-3861(02)00152-0.

[33] Rosík, L.; Virt J.; Masařík, I.; Horák, Z. Studies in ageing of flame retardant high impact polystyrene. Angew. Makromolek. Chem. 1990, 116/111, 311-321. DOI: 10.1002/apmc.1990.051760124.

[34] Huber, S; Ballschmiter, K. Characterisation of five technical mixtures of brominated flame retardants. Fresenius $J$ Anal Chem 2001, 371, 882-890. DOI: 10.1007/s002160101072.

[35] Kelsall, B.J.; Andrew, L. FTIR spectroscopic studies of the matrix photoionization and photolysis products of methylene halides. J. Mol. Spectrosc. 1983, 97, 362-378. DOI: 10.1016/0022-2852(83)90274-6.

[36] Yang, S.; Castilleja, J.R., Barrera, E.V.; Lozano, K. Thermal analysis of an acrylonitrile-butadiene-styrene/SWNT composite. Polym. Degrad. Stab. 2004, 83, 383388. DOI: 10.1016/j.polymdegradstab.2003.08.002. 
387 [37] Fătu, D.; Geambaş, G.; Segal, E.; Budrugeac, P.; Ciutacu, S. On the thermal decomposition of the copolymer ABS and of nylon polyamide. Thermochim. Acta 1989, 149, 181-187. DOI: 10.1016/0040-6031(89)85279-7.

390 
391 Disclosure statement. This is to acknowledge that no financial interest or benefit has arisen to

392 the authors from the direct applications of the research presented in this paper.

393 

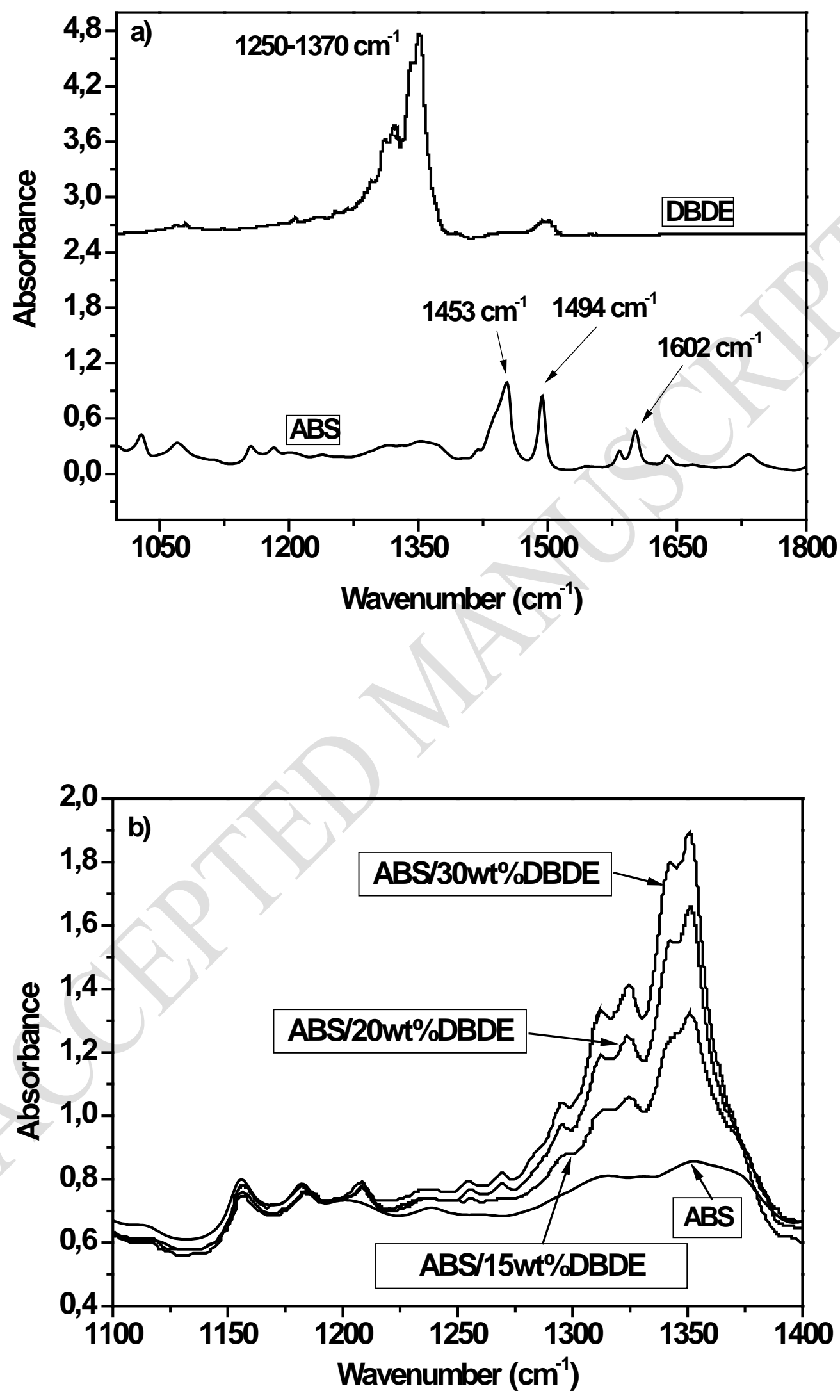
397 Figure 1: a) FTIR spectra of DBDE, ABS, and ABS/DBDE mixtures in the wavenumber 398 range between 1025 and $1800 \mathrm{~cm}^{-1}$. b) Evolution of the intensity of the ether group band of 399 DBDE in ABS/DBDE mixtures with different amounts of DBDE (15wt\%, 20wt\% and $40030 w t \%)$.

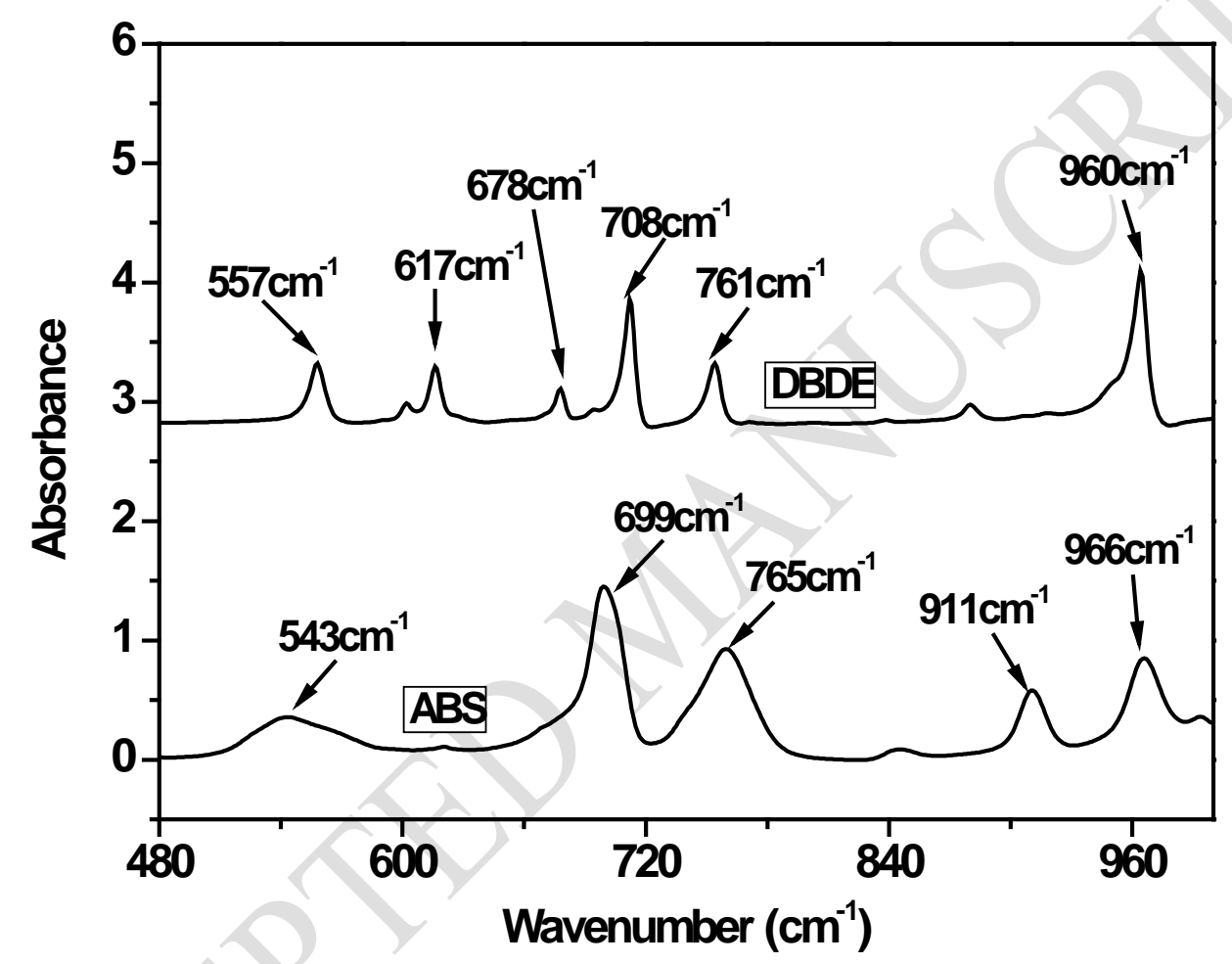

401

402 Figure 2: FTIR spectra of DBDE and ABS in the wavenumber range between 480 and $4031000 \mathrm{~cm}^{-1}$. 


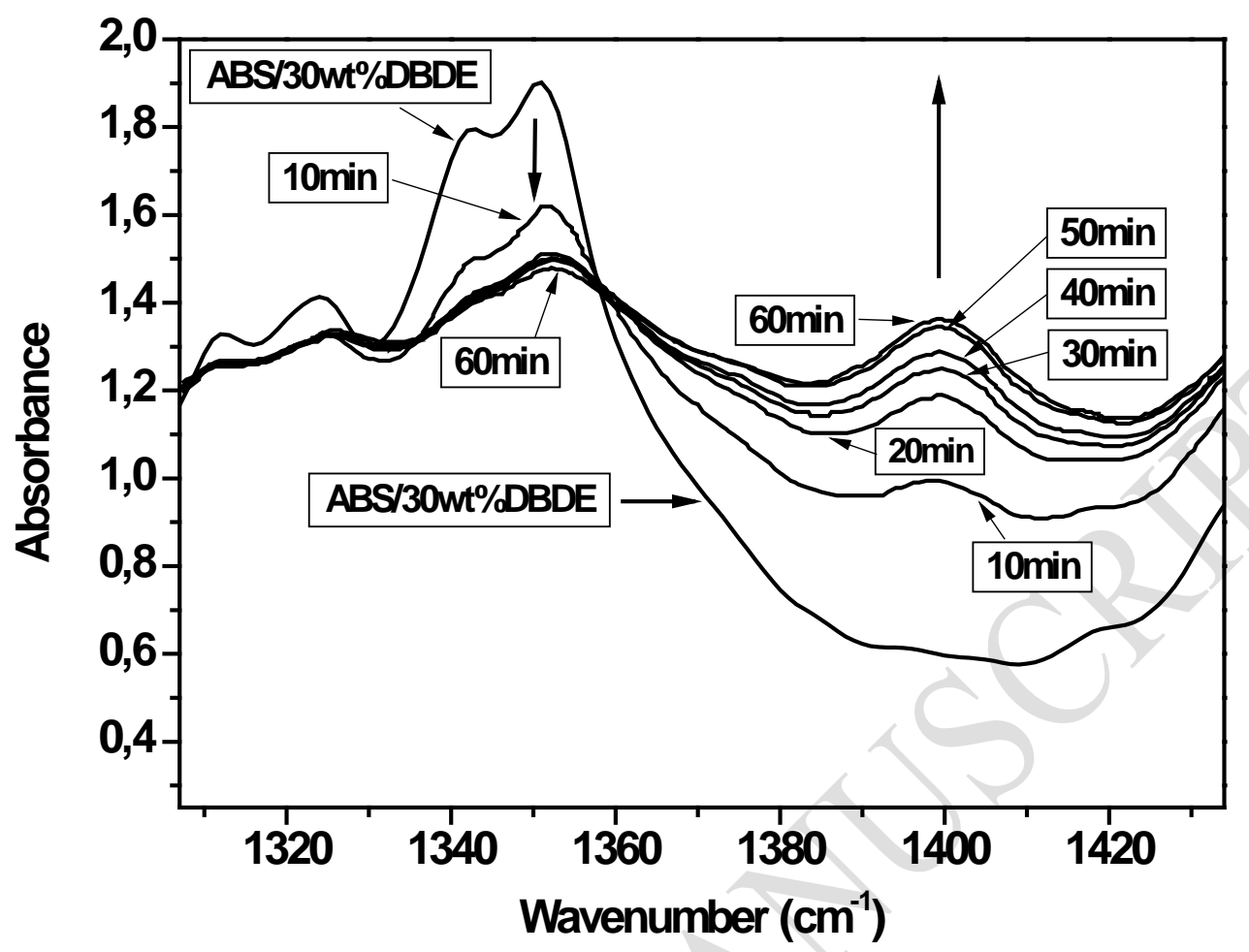

404

405 Figure 3: Evolution of the FTIR spectra between 1300 and $1450 \mathrm{~cm}^{-1}$ of the ABS/30wt-\%

406 DBDE system subjected to radiative UV/Visible treatment as a function of irradiation time. 


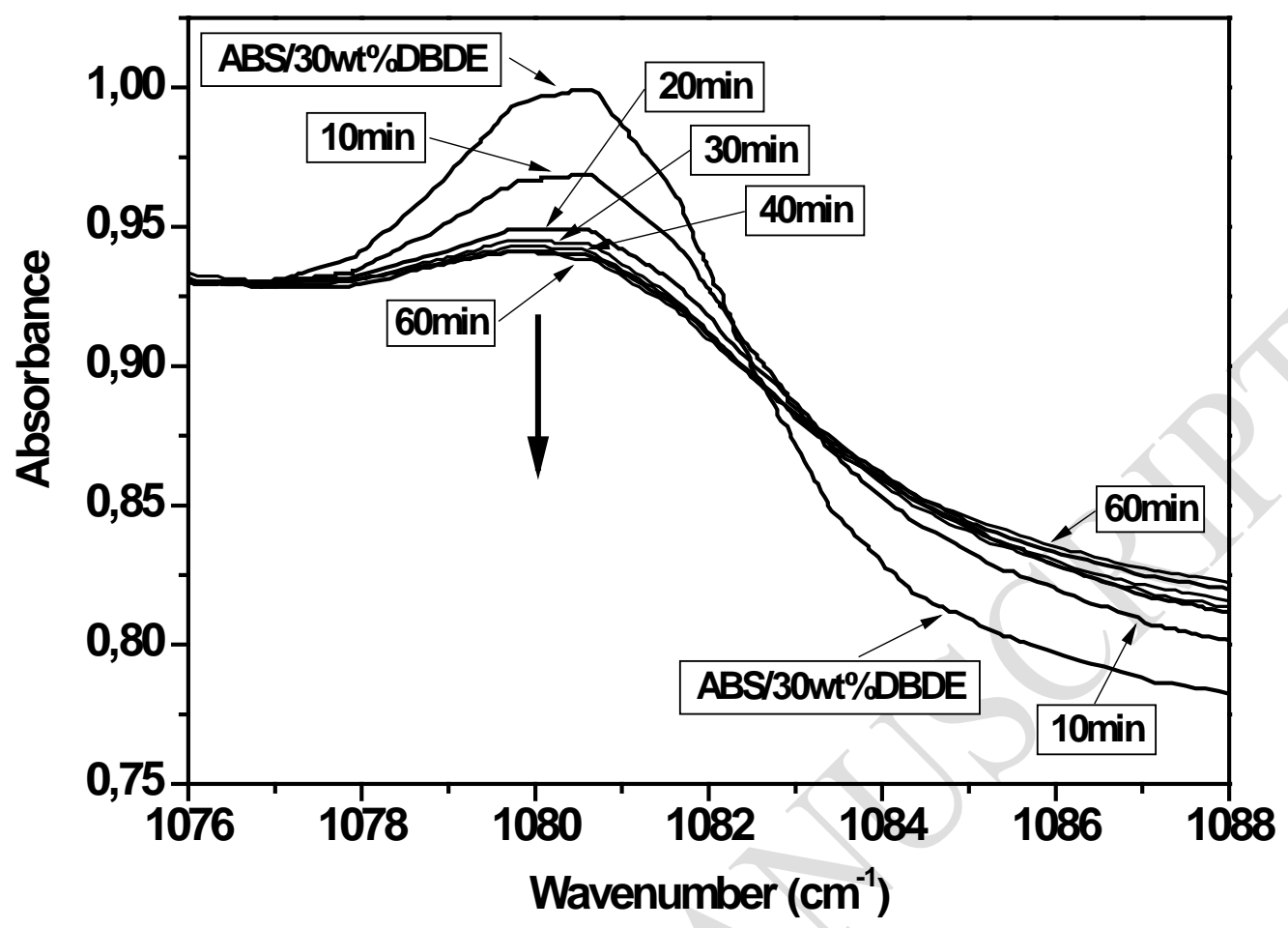

407

408 Figure 4: FTIR spectra of ABS/30wt\% DBDE as function of irradiation time by UV-visible 409 light, in the wavenumber range from $1076 \mathrm{~cm}^{-1}$ to $1088 \mathrm{~cm}^{-1}$. 


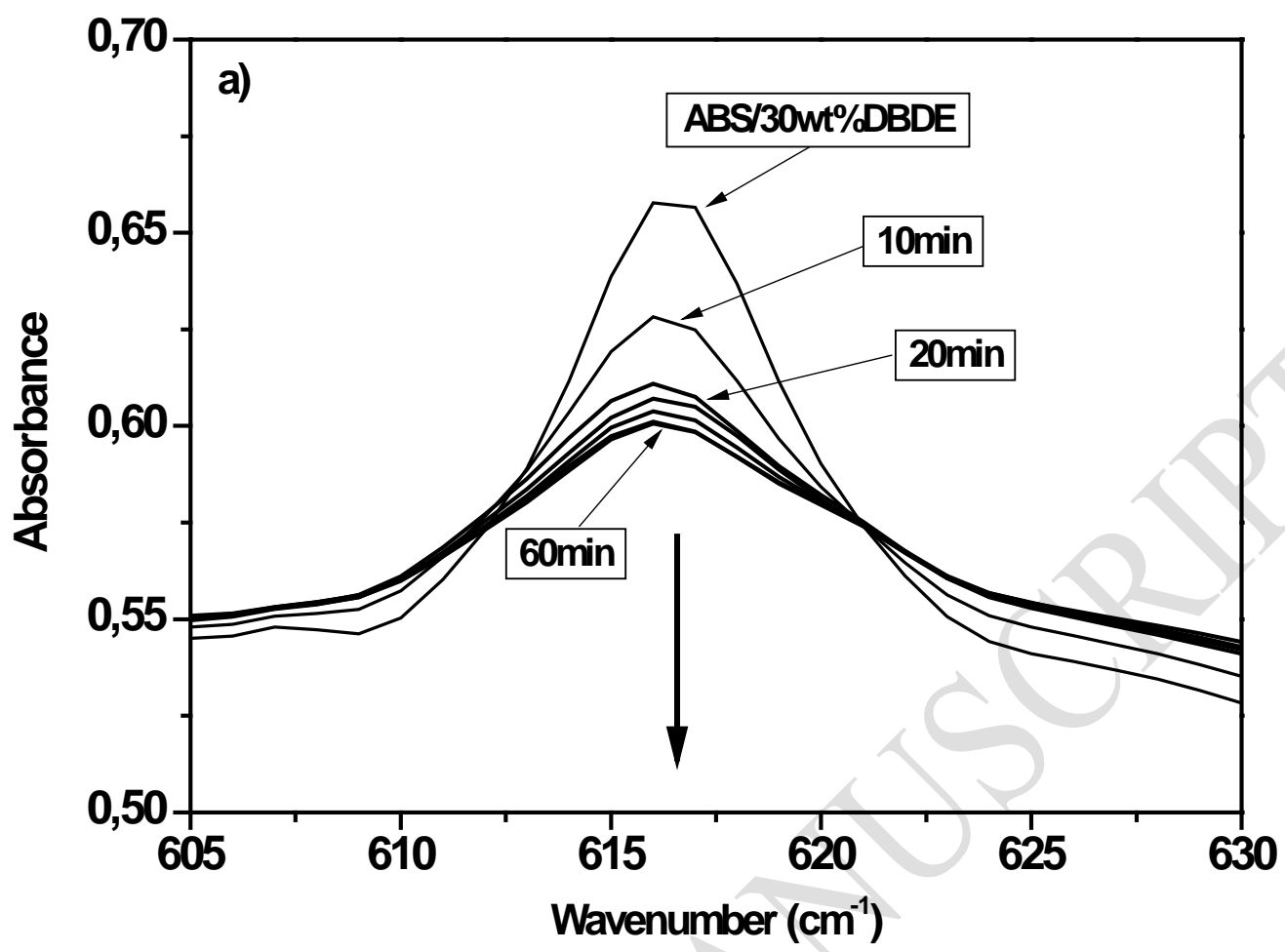

410

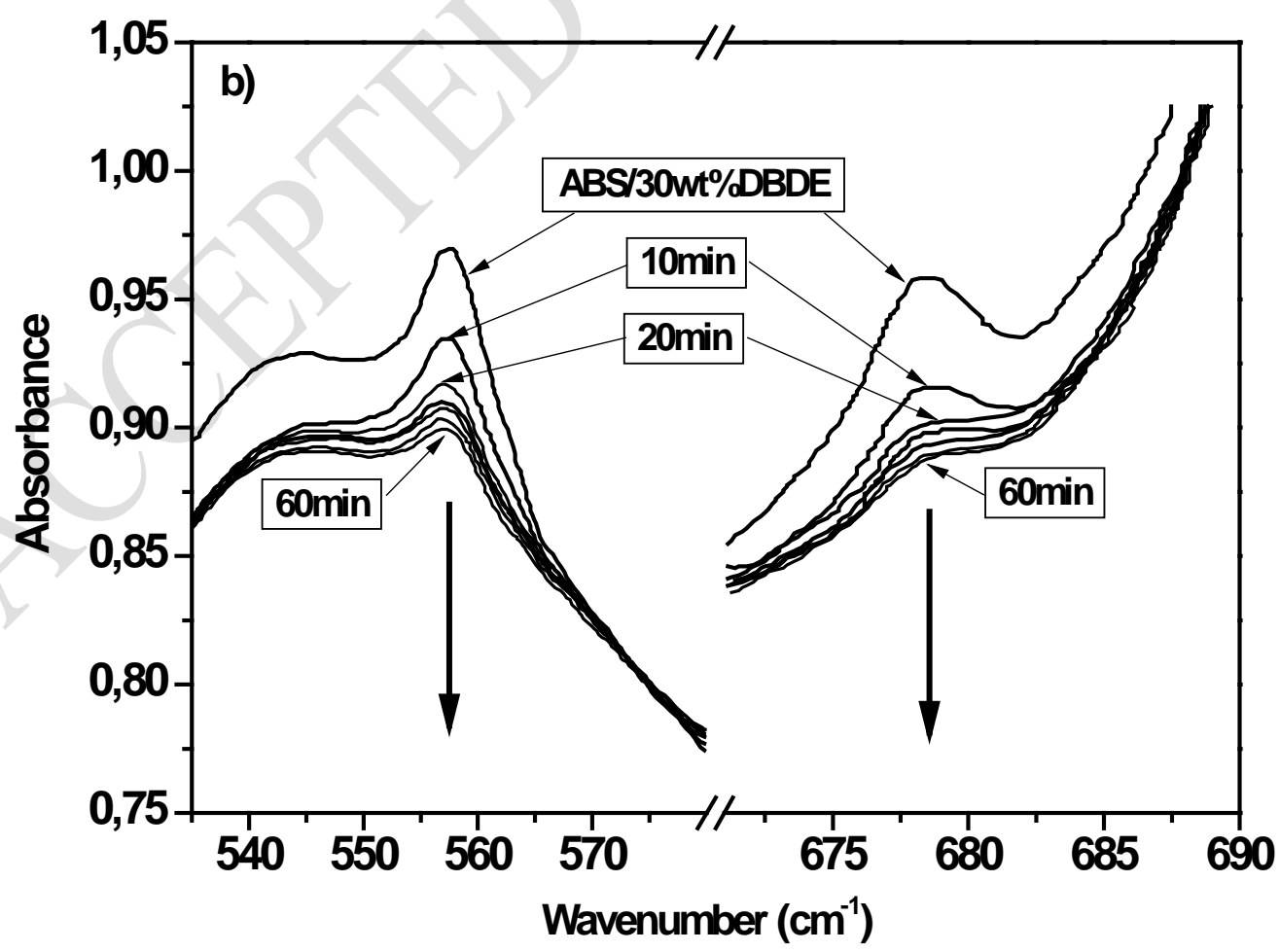

411 
412 Figure 5: Spectral evolution by FTIR of ABS/30wt\% DBDE system during UV/Vis

413 irradiation, in the wavenumber range between a) $605-630 \mathrm{~cm}^{-1}$ and b) $535-580 \mathrm{~cm}^{-1}$ and 670 -

$414690 \mathrm{~cm}^{-1}$

415

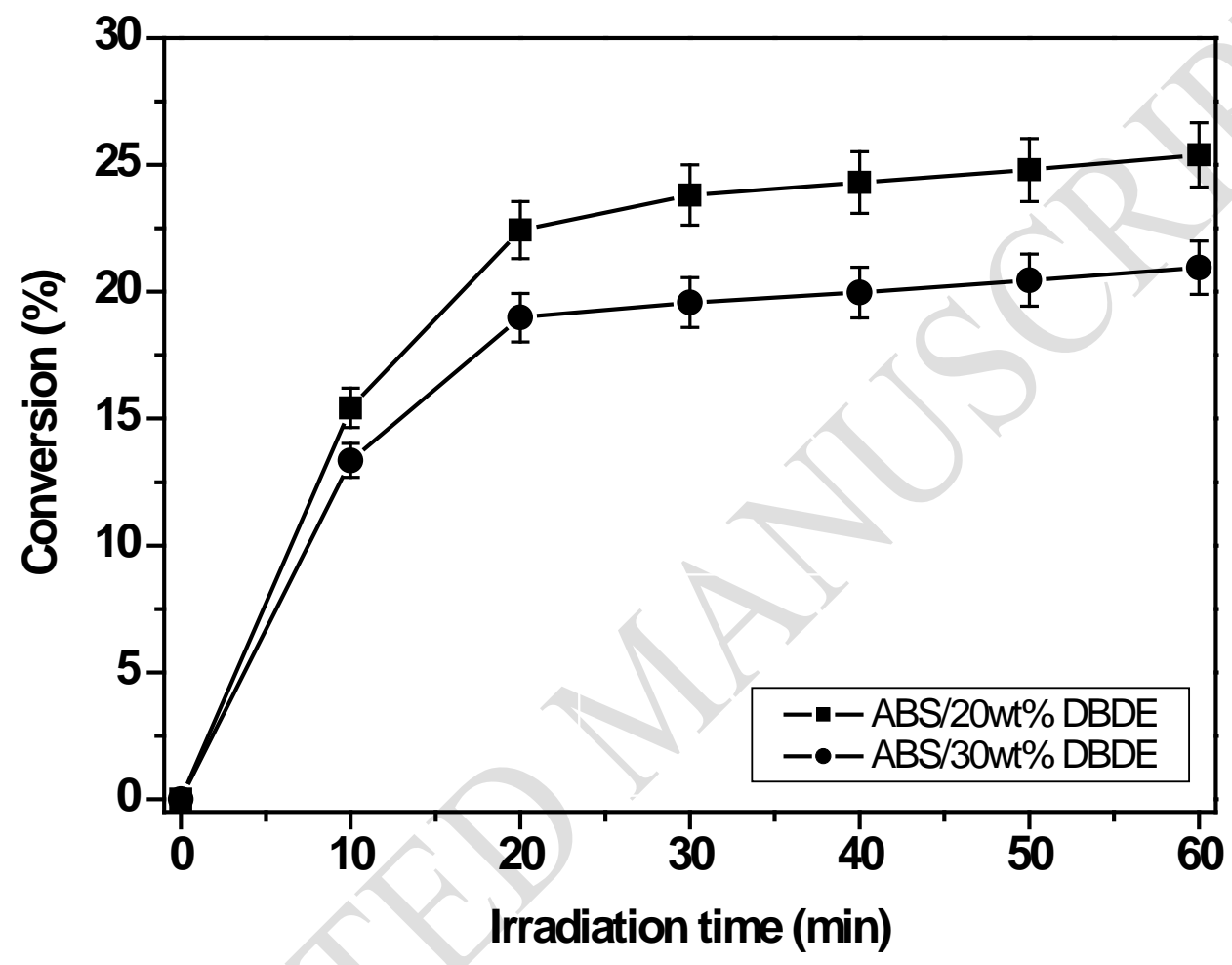

416

417 Figure 6: Effect of the DBDE concentration in ABS/DBDE blends on the conversion values 418 of the photodegradation.

419 


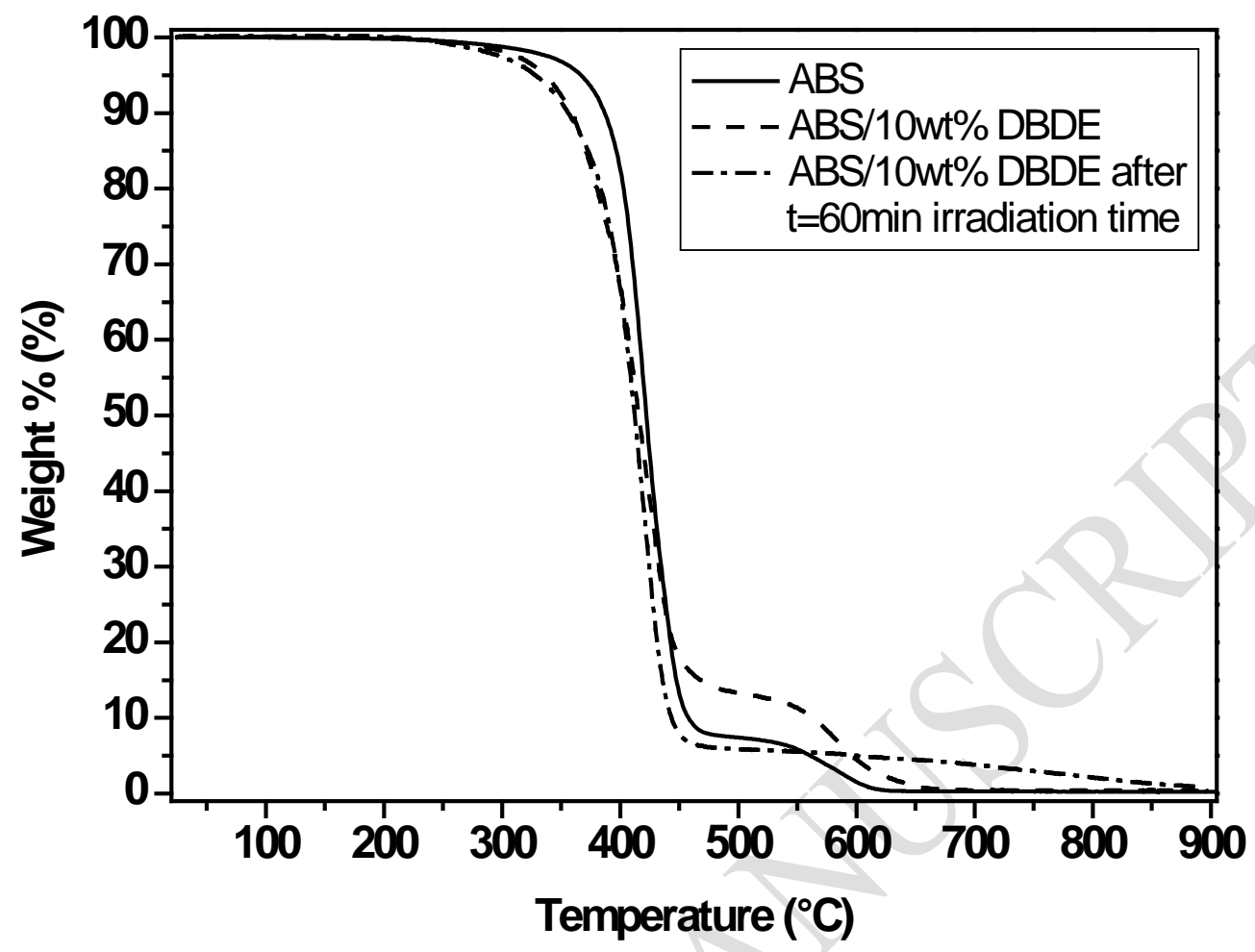

420

421 Figure 7: TGA thermograms of the pure ABS polymer and the ABS/10wt\% DBDE system 422 recorded before and after UV-visible irradiation.

423 